\title{
Ag-Nanostars for the Sensitive SERS Detection of Dyes in Artistic Cross-Sections-Madonna della Misericordia of the National Gallery of Parma: A Case Study
}

\author{
Maria Sole Zalaffi ${ }^{1}$ (D), Ines Agostinelli ${ }^{2}$, Najmeh Karimian ${ }^{1}$ and Paolo Ugo ${ }^{1, *(D)}$ \\ 1 Department of Molecular Sciences and Nanosystems, University Ca' Foscari of Venice, Via Torino 155, \\ 30172 Venezia Mestre, Italy; mariasole.zalaffi@unive.it (M.S.Z.); najmeh.karimian@unive.it (N.K.) \\ 2 Restoration Laboratory of the National Gallery of Parma, Piazzale della Pilotta 15, 43121 Parma, Italy; \\ ines.agostinelli@beniculturali.it \\ * Correspondence: ugo@unive.it
}

Received: 29 September 2020; Accepted: 10 November 2020; Published: 12 November 2020

\begin{abstract}
In historical paintings, the detection of low amounts of pigments and dyes by Raman spectroscopy can sometimes be challenging, in particular for fluorescent dyes. This issue can be overcome by using SERS (surface-enhanced Raman spectroscopy) which takes advantage of the properties of nanostructured metal surfaces to quench fluorescence and enhance Raman signals. In this work, silver nanostars (AgNSs) are applied for the first time to real art samples, in particular to painting cross-sections, exploiting their effective SERS properties for pigment identification. The case study is the Madonna della Misericordia of the National Gallery of Parma (Italy). Cross-sections were analyzed at first by optical microscopy, SEM-EDS, and micro-Raman spectroscopy. Unfortunately, in some cross-sections, the application of conventional Raman spectroscopy was hindered by an intense background fluorescence. Therefore, AgNSs were deposited and used as SERS-active agent. The experimentation was successful, allowing us to identify a modern dye, namely copper phthalocyanine. This result, together with the detection of other modern pigments (titanium white) and expert visual examination, allowed to reconstruct the painting history, postdating its realization from the 15th century (according to the Gallery inventory) to 19th century with a heavy role of recent (middle 20th century) restoration interventions.
\end{abstract}

Keywords: silver nanostars; surface enhanced Raman spectroscopy; cross-sections; copper phthalocyanine; blue pigment; analytical diagnostics; National Gallery of Parma; Madonna della Misericordia

\section{Introduction}

Nowadays the scientific approach plays a key role in the conservation-restoration of cultural heritage, which is necessary not only to sort out conservation issues but also to answer diagnostic inquiries. The analysis of the composition of a work of art follows a precise analytical protocol which starts from the visual analysis (optical microscopy in visible and UV light, IR reflectography), then it involves the use of elemental and molecular non-destructive techniques (X-rays fluorescence spectroscopy), scanning electron microscopy (SEM), attenuated total reflection-Fourier transform infrared (ATR-FTIR) spectroscopy, Raman spectroscopy, up to eventually resorting to micro-destructive ones (gas chromatography and mass spectrometry, high performance liquid chromatography). Indeed, since they are composite materials, works of art must be studied in their three-dimensionality in order to take into account all the layers underneath the superficial one. For this reason, transversal micro-sample, the so-called cross-section, once embedded in resins or salts, represent the ideal condition for an exhaustive analysis. Cross-sections should contain all the layers of which the work of art is composed: 
support, ground layer, priming, paint layer, varnish, and glaze. The complexity of the layering and the variety of material employed (binders, pigments, dyes, varnishes) depend on several factors: the period and place of execution, the artist, the restoration interventions, etc. Cross-sections can tell us the story of a work of art: by performing analyses directly on each layer, we can map the materials employed and organize the layers in a reliable sequence [1,2].

Chemical information on the composition of the layers of a cross-section can be obtained by analytical techniques characterized by spatial resolution capabilities. Typically, localized elemental information is obtained by SEM combined with electron dispersive spectroscopy (EDS) while molecular data are obtained by using vibrational spectroscopies combined with optical microscopy, such as micro-FTIR or micro-Raman spectroscopy.

In particular, Raman spectroscopy represents one of the most employed techniques in diagnostics thanks to the following advantages: non-destructiveness, efficient in situ performance, high spatial resolution (up to $1 \mu \mathrm{m}$ ), presence of Raman bands in the "fingerprint" region of the spectra, capability of discriminating between different crystalline structures, and to resolve weak Raman signals of the analyte from water and glass [3,4]. On the other hand, Raman spectroscopy presents some disadvantages which can hamper its widespread use. Raman scattering is weak (spectroscopic cross-section of $10^{-28} \mathrm{~cm}^{2} / \mathrm{mol}$ ), as a result, it can be obscured by the much more intense fluorescence (spectroscopic cross-section of $10^{-16} \mathrm{~cm}^{2} / \mathrm{mol}$ ) emitted by organic molecules with conjugated electronic structures, such as the colorants. The low sensitivity of Raman spectroscopy and the presence of fluorescence can hinder the detection of dyes, in particular, when present at low concentration levels.

Surface enhanced Raman spectroscopy (SERS), observed for the first time by Fleischmann, Hendra, and McQuillan in 1973 [5], helps to overcome these shortcomings. This technique takes advantage of the optical properties of nanostructured metal surfaces, in particular silver, which locally enhance the electromagnetic field, at the same time quenching the fluorescence. As a consequence, a dramatic enhancement of the Raman signal is detected for molecules in close contact with the nanomaterial so facilitating their detection [6].

The SERS technique has been employed in the field of cultural heritage (see ref. [2] for a recent review), in particular, for the analysis of colorants directly on fibers, micro-fragments, and cross-sections [7-9]. Typically, the materials chosen for this purpose are spherical silver nanoparticles, prepared as colloidal dispersion by using the Lee-Meisel method [10,11]. Recently, other nanomaterials have shown higher effectiveness in producing significant SERS effects, including anisotropic nanostructures such as silver nanostars (AgNSs) [12-15]. Due to their stellate shape composed of a central core and many pods, these particular nanoparticles are expected to absorb photons in different spectral regions, namely around $370-380 \mathrm{~nm}$ and in the near infrared region and, when excited with red-light laser beams, AgNSs show Raman enhancement factors in excess to $10^{6}$ [16-18]. Gold and silver nanostars (Au/AgNSs) can be obtained employing different reagents and reduction methodologies. Among the different synthetic methods proposed for the preparation of AgNSs [13,16-25], the one-pot method recently proposed by A. García-Leis et al. [14,15], looks particularly attractive for its feasibility and reproducibility. It involves the reduction of the metallic precursor $\left(\mathrm{AgNO}_{3}\right)$ by a reducing agent (hydroxylamine) in the presence of a capping agent (trisodium citrate) and additive ( $\mathrm{NaOH})$. Here, we propose for the first time, as far as we know, the use of AgNSs prepared with the above method, to detect dyes in painting cross-sections. The efficiency of AgNSs as SERS substrates has been tested in our lab on other kinds of samples such as thiols adsorbed on metals, including metal nanofibers [15], and lake pigments, indicating the superiority of AgNSs over spherical silver nanoparticles [26].

As a case example, the methodology was applied to cross-sections from the Madonna della Misericordia, an altarpiece kept by the National Gallery of Parma, Italy. The study took advantage of recent restoration intervention on the paint, with the goal to obtain information on the history of this work of art, in particular, to identify original pictorial layers and the role of previous restoration or even repainting interventions. In this study, Raman spectroscopy was applied together with other 
diagnostic tools, demonstrating that SERS with the help of AgNSs is effective in detecting organic and metalorganic dyes at trace levels, which are not detectable by means of "regular" Raman spectroscopy.

A case study is exposed in this paper, illustrating how AgNSs can be applied to a cross section of a real painting for diagnostics purposes, confirming that this kind of SERS substrate can be effective for the sensitive detection of organics and metallorganics employed in the field of cultural heritage.

\section{Materials and Methods}

\subsection{The painting "Madonna della Misericordia" from the National Gallery of Parma}

The Madonna della Misericordia (Inv. 450) at the National Gallery of Parma is an oil on panel painting, $192 \times 82 \mathrm{~cm}$, which represents Virgin Mary housing under her mantle the clients, two ladies and two gentlemen, kneeling at her left and right, respectively. It is completed by a painted frame characterized by two lateral paraste, a central rose and a predella decorated by three saints (Figure 1).

a)

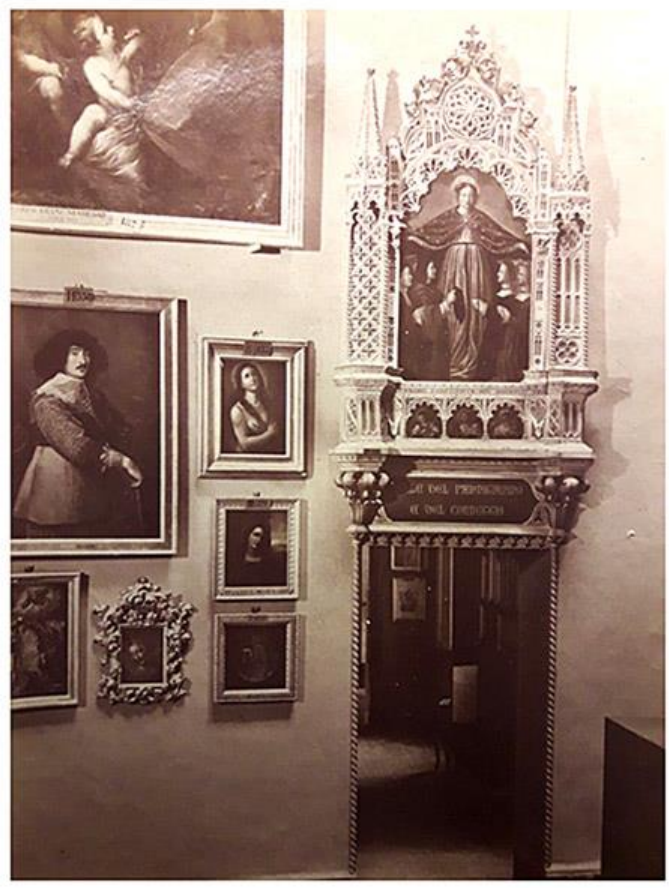

b)

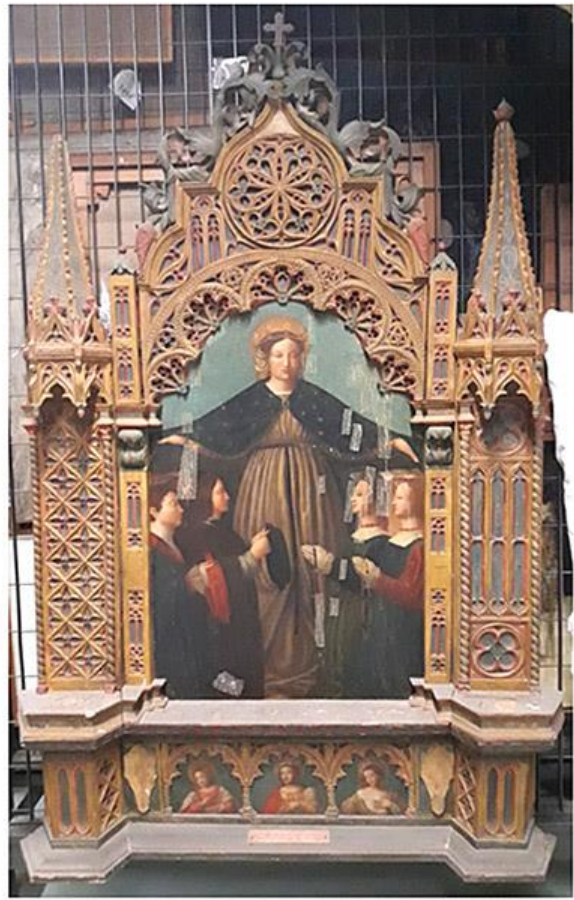

Figure 1. Pictures showing the Madonna della Misericordia (a) at the entrance of Parmigianino and Correggio's display rooms in the 19th century and (b) in the picture gallery where it has been displayed until 2018.

This painting arrived at the Gallery in 1868, coming from the Cappuccini's monastery in Borgo Santa Chiara, Parma [27]. The director of the Gallery, Corrado Ricci, attributed this painting to an anonymous painter belonging to the school of Cremona of the 15th century [28]. The painting underwent important restoration interventions (insertion of wedges into the panel to level it-sverzatura—which is the main cause of cracks on the pictorial layer, numerous re-paintings, etc.) carried out in 1896 by G. Frenguelli [28] and in 1951 by L. Arrigoni [29]. The present study was performed during a restoration intervention of the painting performed in 2018 and 2019.

\subsection{UV-Visible Absorption Spectroscopy}

UV-Visible absorbance spectra were recorded with a Perkin-Elmer Lambda 40 spectrophotometer equipped with a Peltier-Elmer PTP6 (Peltier temperature programmer) apparatus. The Ag colloids samples were diluted 1:3 in water. 


\subsection{Transmission Electron Microscopy (TEM)}

Transmission electron microscopy (TEM) and high resolution TEM (HRTEM) analysis were performed using a JEOL 3010 high resolution electron microscope $(0.17 \mathrm{~nm}$ point-to-point resolution at Scherzer defocus), operating at $300 \mathrm{kV}$, equipped with a Gatan slow-scan CCD camera (model 794) and an Oxford Instrument EDS microanalysis detector Model 6636. Drops of colloidal solutions were deposited on holey-carbon copper grids and let dry at room temperature before analysis.

\subsection{SEM-EDS}

SEM and EDS analysis on selected spots of the cross sections were performed at the University Ca' Foscari of Venice (Department of Molecular Sciences and Nanosystems), using a TM3000 Hitachi tabletop scanning electron microscope coupled with a X-ray microanalysis system (SwiftED3000); conditions for recording the EDS spectra were: acquisition time $30.0 \mathrm{~s}$; process time $5 \mathrm{~s}$; accelerating voltage $15 \mathrm{kV}$.

\subsection{Micro-Raman Spectroscopy}

The SERS measurements were performed at the University of Southampton, during a stage of MSZ at the School of Chemistry. A Renishaw 2000 Raman spectrometer was employed to carry out both Raman and SERS measurements. The excitation laser employed was a Renishaw $785 \mathrm{~nm}$ laser and a CCD detector. The maximum power of the laser is $100 \mathrm{~mW}$, but lower powers were used during the data acquisition, typically $0.05 \%$ and $1 \%(0.05$ and $1 \mathrm{~mW})$ to avoid to damage the samples. The collection time was $10 \mathrm{~s}$ for one accumulation. The spectrometer was equipped with a Leica DMLM series microscope. In order to collect scattered light at the sample, a microscope objective with a 50× magnification was employed with a short working distance $(0.37 \mathrm{~mm}-$ numerical aperture 0.75$)$. Noise filters and background correction were used for clarity when necessary.

\subsection{Preparation of the Cross-Sections}

The samples for the cross sections were taken by the restorer, using a micro scalpel, cutting triangular millimeter sized fragments containing all the layers composing the painting. Then, they were placed into cells of a silicon rubber mold on an already hardened resin layer. At this point, the embedding resin was prepared under the fume hood using some $\mathrm{mL}$ of unsaturated orthophtalic polyester resin (purchased from G. Angeloni, Venice) and few drops of hardener (methyl-ethyl-ketone peroxide). The components were stirred until the mixture was completely homogenous. Eventually, the resin was poured into the cells and left to dry for two days. Once the resin cured, the polishing procedure started. The cross sections were polished manually using silicon carbide paper with decreasing grain sizes. Different grit size were used (P120-P500-P800-P4000-P6000-P8000-12000, of an average size from 130 to $4 \mu \mathrm{m}$ ) and progressively replaced into the lapping machine, equipped with a magnetic rotating disk and water cooling system, from the coarsest to the finest one. The sections were pressed onto the abrasive papers for some minutes and frequently observed at the stereomicroscope to check the level of polishing. This procedure ended when the samples were reached from the long side of the resin blocks.

\subsection{Ag Nanostars Colloid: Preparation and Application on the Cross Sections}

AgNSs were synthesized using the method proposed by A. García-Leis et al. [14], using analytical grade reagents and water purified with a Milli-Q system (Millipore). Four solutions were required:

- Sodium hydroxide solution: $\mathrm{NaOH}(0.02 \mathrm{~g})$ dissolved in water $(10 \mathrm{~mL})$ to get a $0.05 \mathrm{M}$ solution.

- Hydroxylamine solution: $\mathrm{NH}_{2} \mathrm{OH}(18 \mu \mathrm{L})$ at $50 \% \mathrm{w} / \mathrm{v}$ in water $(5 \mathrm{~mL})$.

- Silver nitrate solution: $\mathrm{AgNO}_{3}(0.0017 \mathrm{~g})$ dissolved in water $(10 \mathrm{~mL})$ to obtain a $1 \cdot 10^{-3} \mathrm{M}$ solution.

- Trisodium citrate solution: of $\mathrm{C}_{6} \mathrm{H}_{5} \mathrm{O}_{7} \mathrm{Na}_{3} \cdot 2 \mathrm{H}_{2} \mathrm{O}(0.114 \mathrm{~g})$ dissolved in water $(10 \mathrm{~mL})$ to get a 0.045 M solution. 
Next, $500 \mu \mathrm{L}$ of the $\mathrm{NaOH}$ and $500 \mu \mathrm{L}$ of the hydroxylamine solutions were mixed in a flask and stirred at $670 \mathrm{rpm}$ with a magnetic stirrer for one minute. Then, $9 \mathrm{~mL}$ of the $\mathrm{AgNO}_{3}$ solution were added and the mixture kept under stirring for $5 \mathrm{~min}$. Afterwards, $100 \mu \mathrm{L}$ of the citrate solution were dropped in the flask, stirring for approximately $15 \mathrm{~min}$, i.e., until it developed a dark green color. The reduction of $\mathrm{Ag}^{+}$ions was achieved by hydroxylamine, but this process, at room temperature, is very slow. In order to make the long arms of these spiky nanoparticles grow faster, citrate was added. The complete growth of the star-shaped NPs, starting from a spherical faceted morphology, takes more or less $48 \mathrm{~h}$. Therefore, the colloidal solution of AgNSs was concentrated by centrifuging three times at $8000 \mathrm{rpm}$ in a $1.5 \mathrm{~mL}$ Eppendorf centrifuge tube from $500 \mu \mathrm{L}$ of colloid. After each centrifugation step, $400 \mu \mathrm{L}$ of supernatant were removed and replaced by the same quantity of colloid. Before centrifuging, nanoparticles which got stuck at the bottom, were redispersed. After this procedure, $2 \mu \mathrm{L}$ of the concentrated AgNSs dispersion were deposited on the cross section by means of a micropipette. Once completely dried, the sample was ready to be analyzed with the $\mu$-Raman spectrometer.

\section{Results and Discussion}

\subsection{Synthesis and Characterization of AgNSs}

The macroscopic optical properties and TEM image of the AgNSs are shown in Figure 2, while Figure S1 shows the extinction spectra of the colloidal suspension of AgNSs [16]. This colloid presents a dark green color (Figure 2A) and, as shown by TEM analysis, is indeed composed by a monodisperse suspension of AgNSs (Figure 2B). A typical AgNS presents a central core of around $50 \mathrm{~nm}$ diameter and a variable number of pods arranged in an octahedral structure reaching an overall dimension of approximately $200 \mathrm{~nm}$. The growth starts from spherical seeds of Ag reduced by hydroxylamine, then, in the following $48 \mathrm{~h}$, the pods start taking shape thanks to the citrate ions in the presence of $\mathrm{NaOH}$, which directs the growth of the branches [14,15].

A)

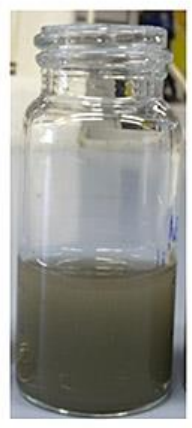

B)

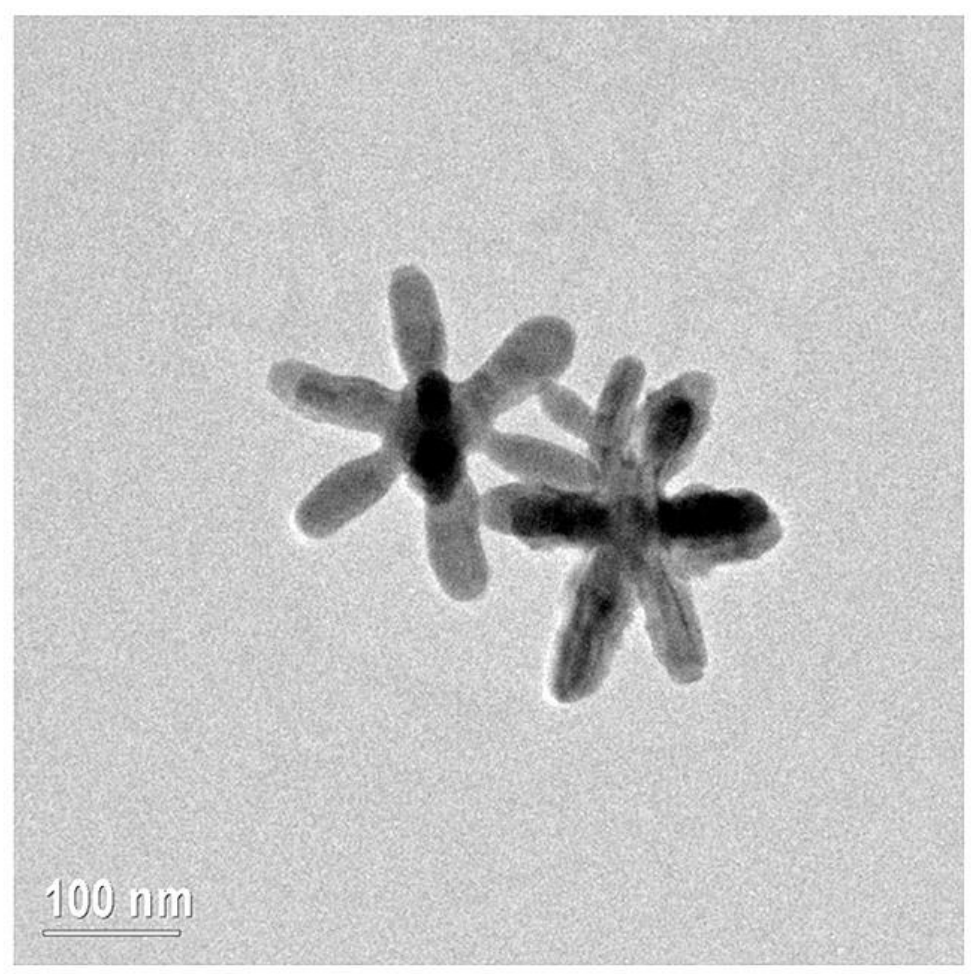

Figure 2. (A) Photograph showing the macroscopic appearance of the colloidal suspension of Ag nanoparticles; (B) relevant TEM image of the nanoparticles obtained. 
The UV-Vis-NIR extinction spectrum of the colloidal dispersion of AgNSs (see Figure S1) presents features in agreement with the previous literature [15-17], namely an absorption peak with maximum extinction at $370 \mathrm{~nm}$, followed by a progressive increase in extinction in the NIR region, starting approximately for $\lambda>550 \mathrm{~nm}$. Further details on the general characterization of the AgNSs synthesized here are described elsewhere [16].

\subsection{Cross-Sections Analysis: Bluish Background (CS7), an Exemplificative Study}

The preliminary analyses were fundamental to plan the sampling areas (see SM). Indeed, mapping the more recently retouched areas of over painting was necessary to avoid them during the sampling. Seven cross-sections were sampled from the painting and the predella, and six from the frame. Each one was taken in order to answer specific questions about the materials employed in every layer of the stratigraphy at those precise points (Figure 3). For the sake of brevity, only the most important and relevant results are presented (see SM).

a)

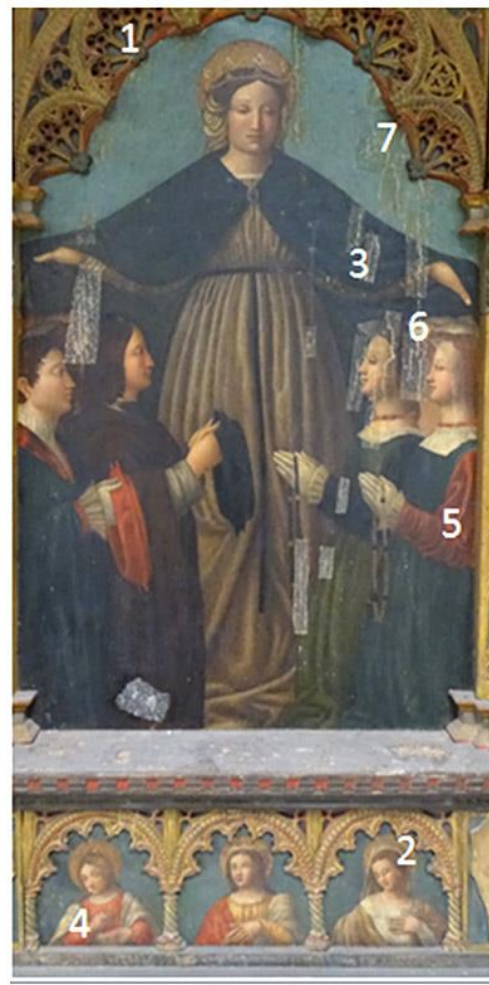

b)

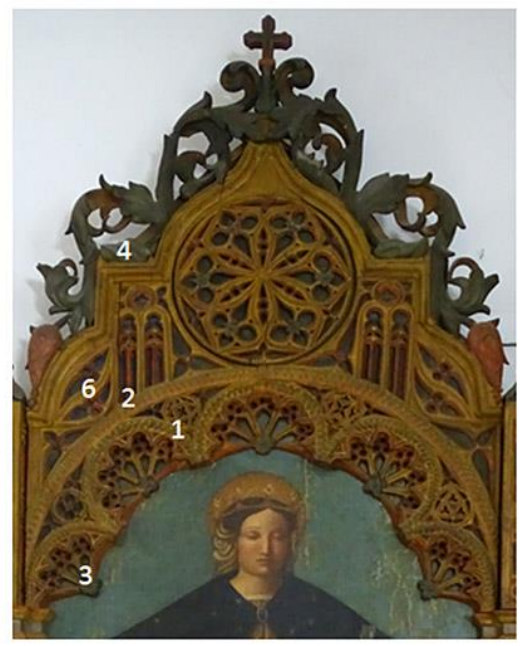

Figure 3. Sampling map of the numbered cross sections (CS) in the (a) panel and (b) frame (CS5 is an erratic sample).

The analysis of CS7, sampled in the bluish background behind the Virgin Mary and the clients, is the most exemplificative in the context of the present study. Figure 4a shows the exact area where CS7 was sampled and, once embedded in a polyester resin block, it was analyzed using $50 \times$ magnification (Figure $4 \mathrm{~b}$ ) and optical microscope in reflected light (Figure 4c). At high magnifications (50x), all the layers composing the painting are visible. Starting from the bottom, we can find the ground layer, made of gypsum, which is necessary to make the support even and homogeneous, in this case, the wood panel. Then, it is possible to note the paint layer made up of a mixture of blue and white grains. The peculiar feature is that this sequence is repeated: a new ground and paint layer were added on the original ones in more recent times. Apparently, they may be composed of the same materials, but this must be investigated by means of elemental and molecular analyses.

First of all, the cross section was examined by SEM. The analysis of data in Figure 5 confirms the presence of four layers: the 1st ground (I) (around $150 \mu \mathrm{m}$ ), characterized by light elements 
(darker areas); the 1st paint layer (II) $(\approx 70 \mu \mathrm{m})$ composed by grains of quite light elements in a heavier matrix (brighter areas); the 2 nd ground layer (III) $(\approx 50 \mu \mathrm{m})$ and the 2 nd paint layer (IV) $(\approx 15 \mu \mathrm{m})$, both containing mainly light elements with some brighter spots which indicate the presence of heavy elements. EDS analysis provided important information on the elemental composition of the layers. EDS spectra inserted in Figure 5 confirm the presence of $\mathrm{Ca}$ and $\mathrm{S}$ in the 1st ground layer, which agree with the likely use of gypsum $\left(\mathrm{CaSO}_{4}\right)$. The peak of $\mathrm{Cu}$ in the grains and the one of $\mathrm{Pb}$ in the matrix of the 1st paint layer suggest the presence of a blue copper pigment such as azurite $\left[\mathrm{Cu}_{3}(\mathrm{CO})_{2}(\mathrm{OH})_{2}\right]$ mixed with a white lead pigment, probably lead white $\left[\left(\mathrm{PbCO}_{3}\right)_{2} \cdot \mathrm{Pb}(\mathrm{OH})_{2}\right]$. Ca and $\mathrm{S}$ are detected also in the 2nd ground layer, indicating again the presence of gypsum. Finally, the 2nd paint layer is mainly characterized by the presence of $\mathrm{Ti}, \mathrm{Si}, \mathrm{Al}, \mathrm{Na}, \mathrm{S}, \mathrm{Cu}$, and some $\mathrm{Cr}$. The presence of Ti suggests the use of titanium white, $\mathrm{TiO}_{2}$, a modern pigment introduced in 1920 [30].

Additional EDS spectra were recorded, focusing on the bluish grains present in the 2nd paint layer, revealing the presence of $\mathrm{S}, \mathrm{Ba}, \mathrm{Cr}$, and $\mathrm{Co}$ (see Figure 6). The detection of $\mathrm{S}$ and $\mathrm{Ba}$ can agree with the presence of barite, $\mathrm{BaSO}_{4}$. This natural occurring mineral has been synthetically produced from the beginning of the nineteen century to be extensively employed both as filler in the formulations of colors [31] and used in the preparation of $\mathrm{TiO}_{2}$ [30]. $\mathrm{Cr}$ and $\mathrm{Co}$ could be attributed to the presence of a bluish chromium-based pigment: cobalt chromite, $\mathrm{CoCr}_{2} \mathrm{O}_{4}(\mathrm{~PB} 36$, cobalt chromite blue-green spinel) often substitutes the historically genuine cerulean blue (PB35, cobalt stannate), the latter being introduced in 1860 as a pigment [32]. Unfortunately, no Raman or SERS spectral evidence allowed to confirm this supposition.

a)

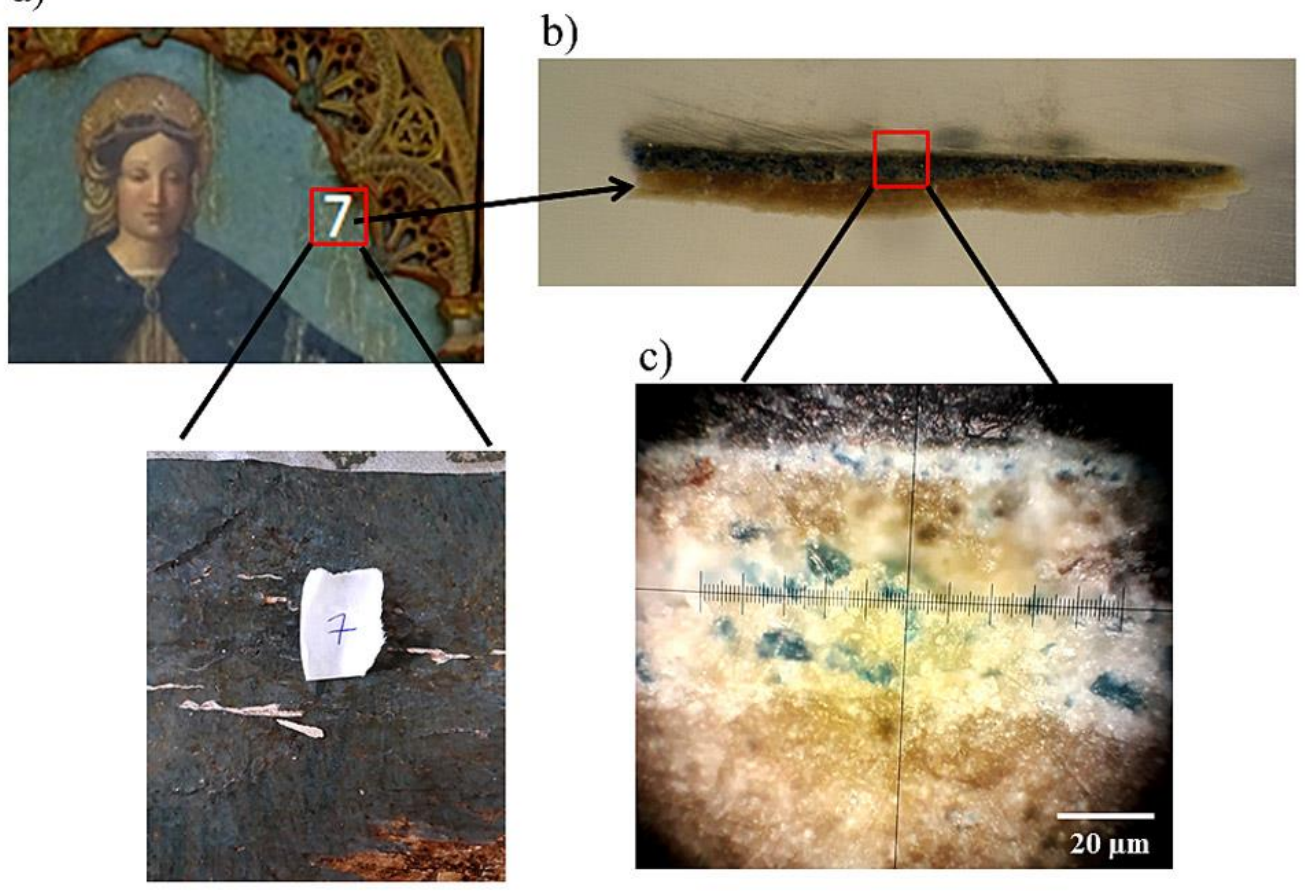

Figure 4. (a) The sampling area of CS7 is marked on the picture; (b) CS7 analyzed using the stereomicroscope, a transversal sample $(1-2 \mathrm{~mm})$ embedded in a resin block showing all the layers the painting is composed of; (c) magnification of the cross section (objective of the microscope 50×) showing from the bottom to the top the original ground and paint layer and a more recent coat composed of a new ground and paint layer. 

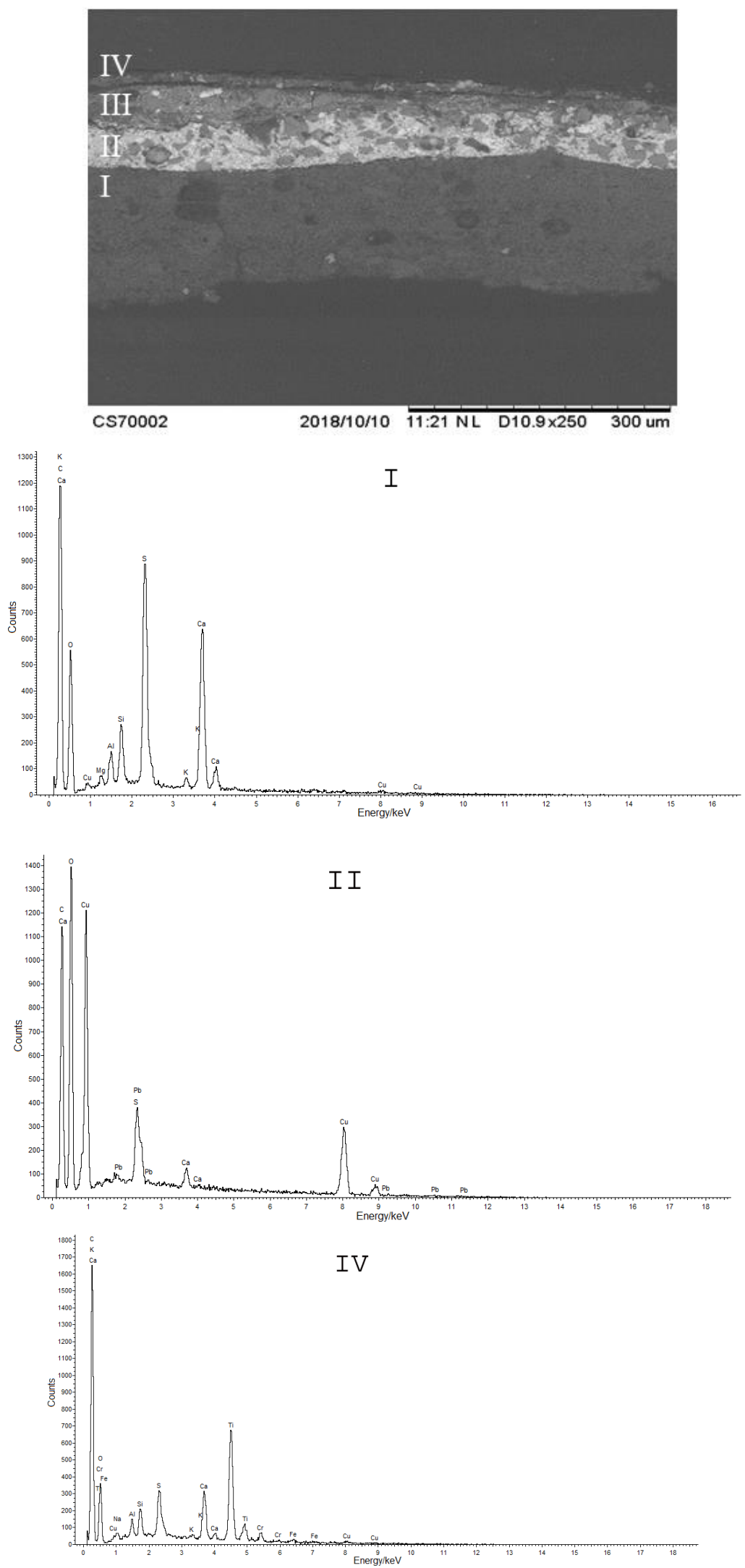

Figure 5. SEM image of CS7 and EDS spectra recorded on the I, II, and IV layers (the EDS spectrum of the III layer is comparable with that of layer I). 
In order to obtain information at a molecular level, micro-Raman spectroscopy was applied. Figure 7 shows the Raman spectra recorded analyzing defined points on the magnified cross section, indicated in Figure 7a. The two ground layers were confirmed to contain gypsum, whose spectrum presents the typical band at 1009 (strong) $\mathrm{cm}^{-1}$ (Figure 7b) [33]. Comparison with literature spectra [33] proved that the 1st paint layer contains azurite, as indicated by the bands at 1578 (weak), 1423 (medium), $1096(\mathrm{~m}), 832(\mathrm{w}), 770(\mathrm{~m}), 401(\mathrm{~s}), 247$ and $83(\mathrm{~m}) \mathrm{cm}^{-1}$ (Figure 7c), and lead white, whose bands are detected at 1055 (s) and $401(\mathrm{~m}) \mathrm{cm}^{-1}$ (Figure $7 \mathrm{~d}$ ).

The results of the Raman analyses performed on the 2nd paint layer are exposed below. The presence of titanium white (PW6) in the form of anatase, was confirmed by the detection of its typical bands at $640(\mathrm{~m}), 510(\mathrm{~m}), 397(\mathrm{~m})$ and $143(\mathrm{~s}) \mathrm{cm}^{-1}$ (Figure 8) [32].

The Raman characterization of the bluish pigment, due to the scarcity of grains and the tiny thickness of the layer, is particularly challenging. The Raman spectrum recorded on this layer allowed us to identify ultramarine blue: sodium polysulphide-aluminosilicate (PB29, $\mathrm{Na}_{6-10} \mathrm{Al}_{6} \mathrm{Si}_{6} \mathrm{O}_{24} \mathrm{~S}_{2-4}$, which is responsible for the Raman band at $548 \mathrm{~cm}^{-1}$ (s) (the bands in gray belong to titanium white) (Figure 9) [34]. This attribution is supported by the detection of Si, Na, Al, S in the EDS spectrum reported in Figure 5IV. Natural ultramarine is a mineral called lazurite, a complex sulfur-containing sodium aluminosilicate based on a body-centered cubic lattice. Synthetic ultramarine was synthesized in 1828 by Jean Baptiste Guimet in Paris and then rapidly adopted by artists [35]. Note that natural and synthetic ultramarine blue provide comparable spectral signatures and cannot be distinguished by Raman analysis.

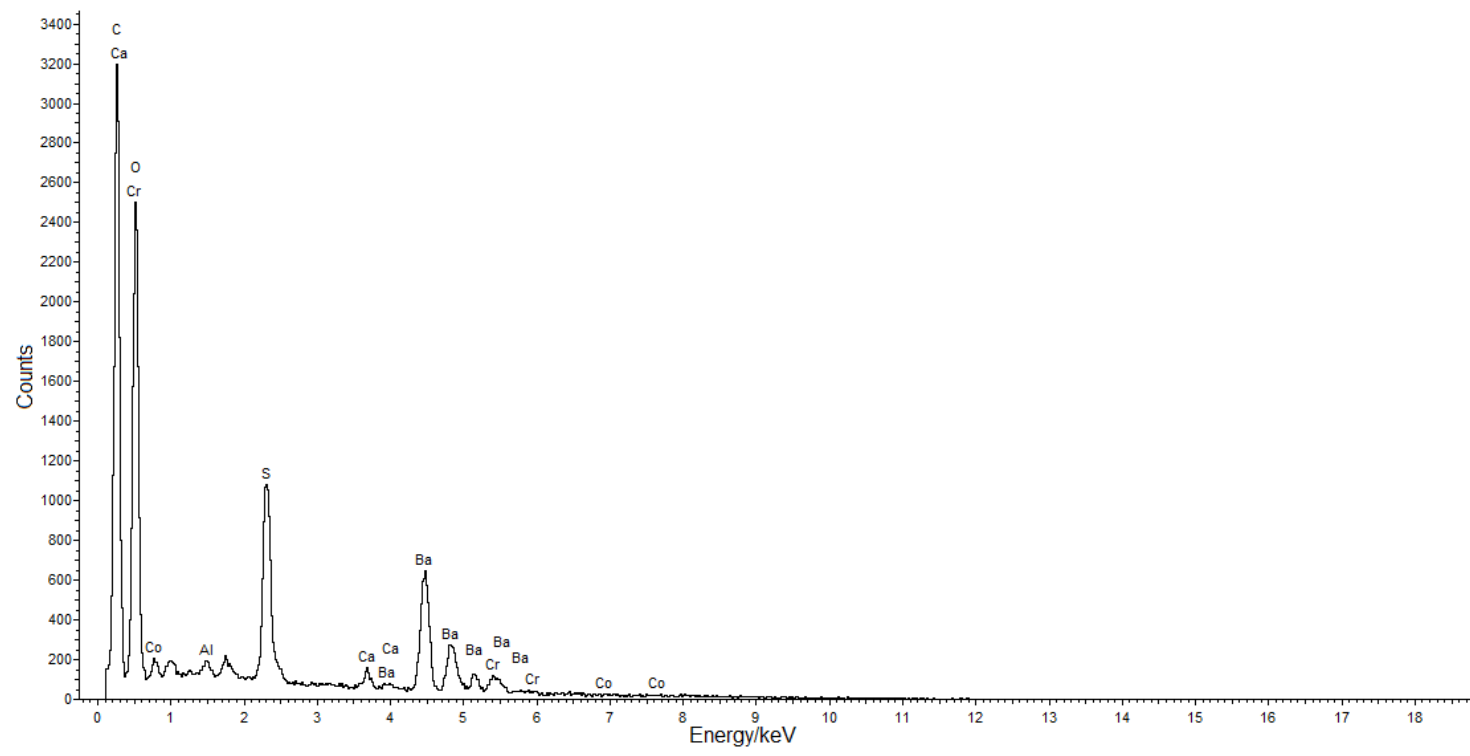

Figure 6. EDS spectrum performed on blue grain of the 2nd paint layer of CS7. 
a)

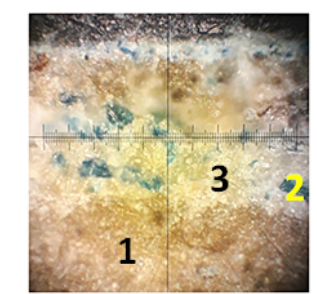

b)

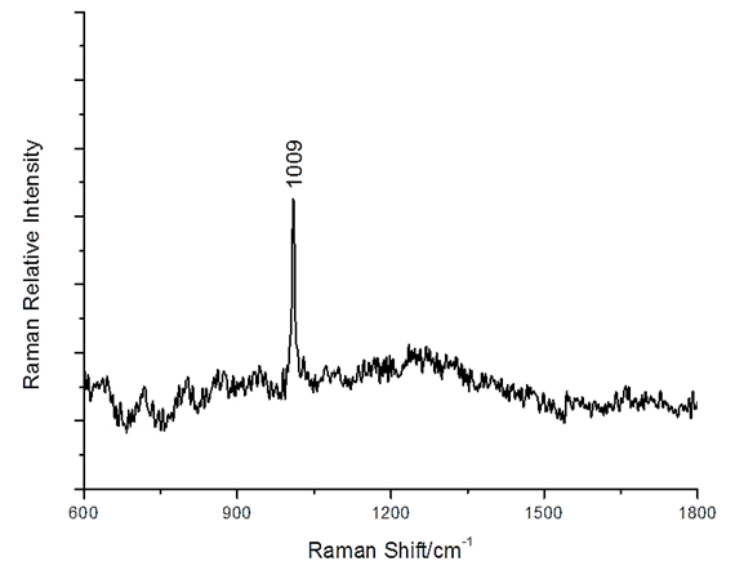

c)

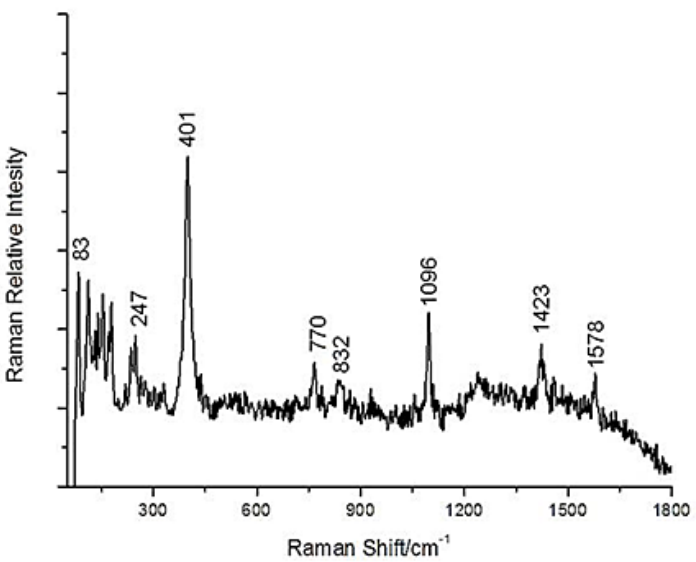

d)

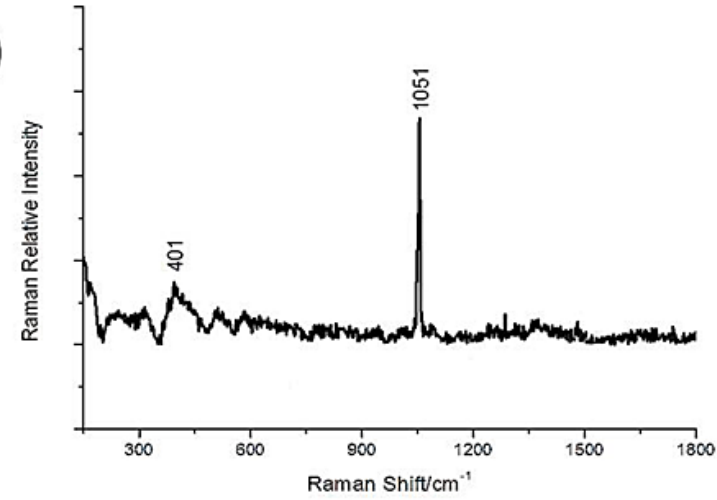

Figure 7. (a) Optical micrograph of CS7 (50×); (b-d) Raman spectra on CS7 revealing: (b) in the 1st and 2 nd ground layers, at point 1, the spectral features typical of gypsum; in the 1st paint layer, (c) at point 2 the features of azurite, and (d) at point 3, of lead white. 

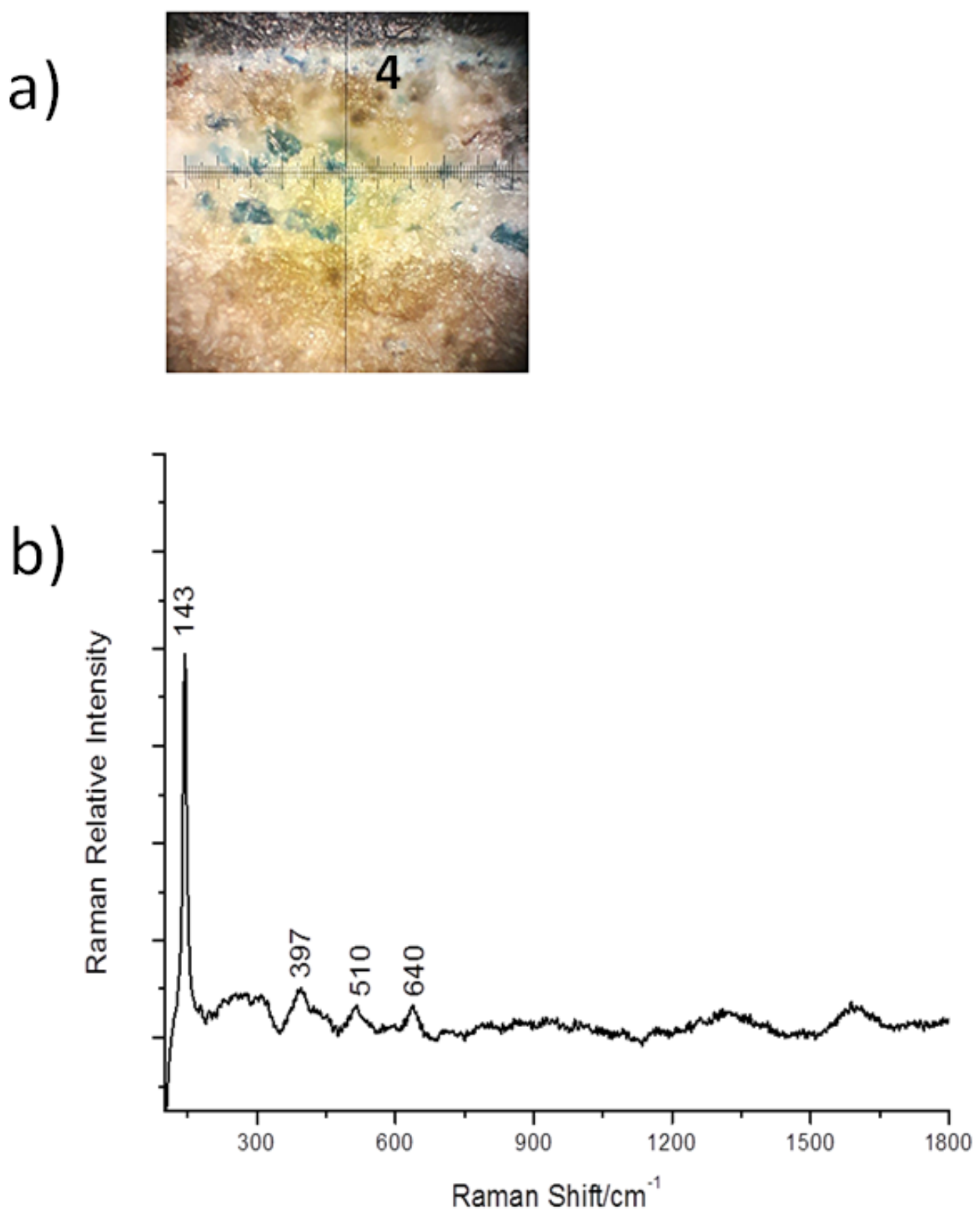

Figure 8. (a) Optical micrograph (50x) and (b) Raman spectrum recorded at point 4 on the 2nd paint layer of CS7, showing the spectral features of titanium dioxide.

During the analysis of the blue layer, we noticed that some spots gave strong fluorescence while others did not. Indeed, the spectrum in Figure 9 refers to the non-fluorescent grains. Comparing the results obtained with the composition of the most common contemporary color tubes, it was clear that the presence of synthetic ultramarine alone was unlikely since this pigment is often mixed with synthetic organic dyes [36]. Normal Raman spectroscopy did not provide spectra useful to solve this diagnostic issue because of the fluorescence, typically generated by some organic dyes and pigments (Figure 10a). For this reason, we opted to employ the SERS technique using AgNSs as signal enhancers and fluorescence quenchers, in order to amplify the Raman spectrum of the fluorescent grains. After addition of the Ag nanostars [14], the spectrum shown in Figure 10b was collected. 
The fluorescent background is now dramatically lowered and a defined spectrum emerges being characterized by detectable bands at $1566(\mathrm{~m}), 1514(\mathrm{~s}), 1438(\mathrm{w}), 1400(\mathrm{w}), 1379(\mathrm{~m}), 1349$ (s), 1303 (m), $1142(\mathrm{w}), 1104(\mathrm{~s}), 1002(\mathrm{~m}), 720(\mathrm{~m}), 679(\mathrm{~s}), 649(\mathrm{~m})$, and $585(\mathrm{w}) \mathrm{cm}^{-1}$. Comparison with literature data indicate that these features corresponds to those of copper alpha-phthalocyanine (PB 15:2) [37-39], a synthetic pigment. A detailed comparison of the experimental and the reference bands of PB 15:2 is reported in Table S1 in Supplementary Materials. Interestingly, the presence of PB 15:2 agrees with the presence of the $\mathrm{Cu}$ signals in the EDS spectrum in Figure 5II. Organic phthalocyanines and their metal complexes were synthesized at the beginning of the twentieth century and are widely used as blue and green pigments until the present time [40]. Note that the band at $211 \mathrm{~cm}^{-1}$ is produced by the interaction of $\mathrm{Ag}$ with ions present in the colloidal solution of nanoparticles [41].
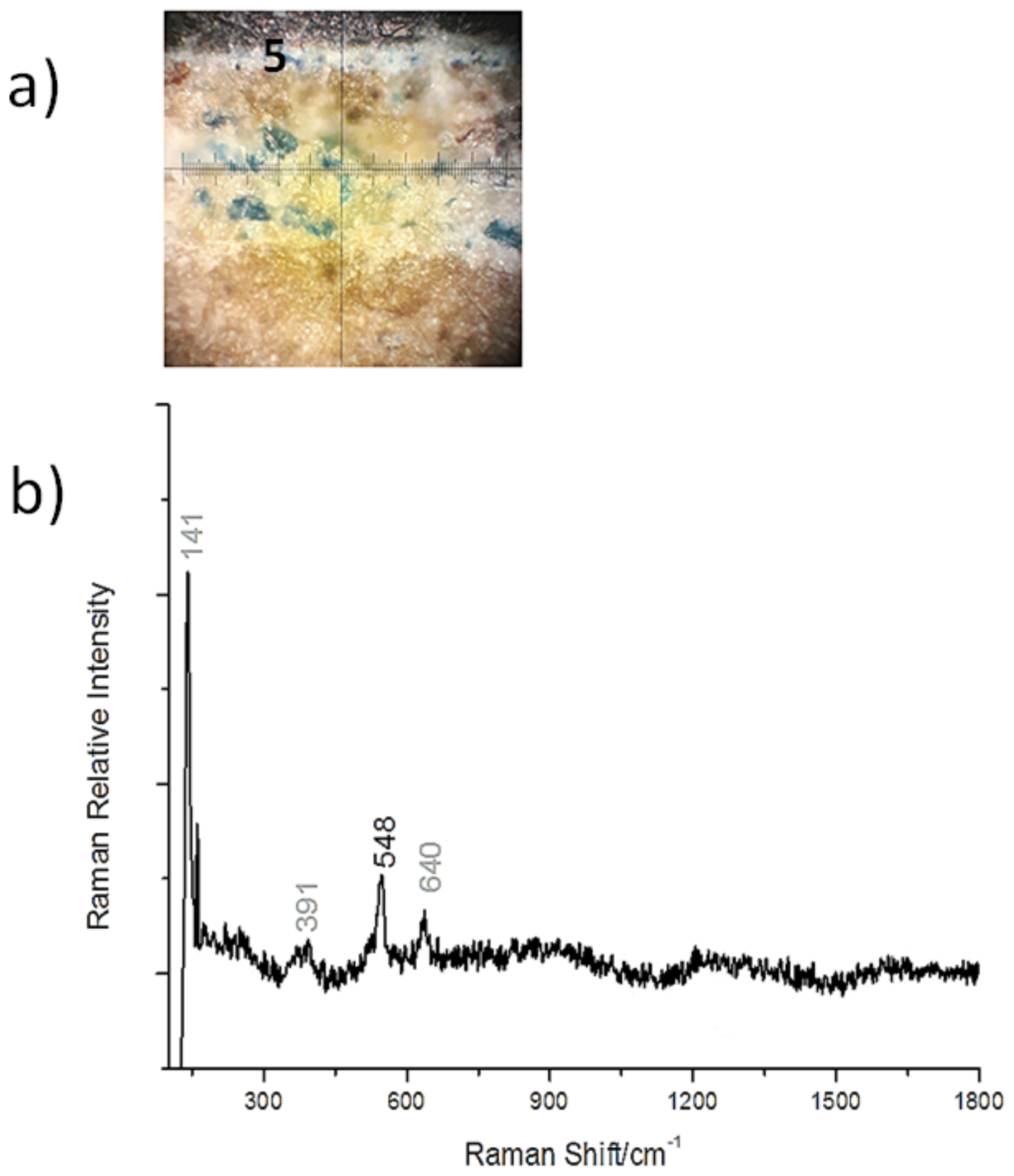

Figure 9. (a) Optical micrograph $(50 \times)$ and (b) Raman spectrum recorded at point 5 on the 2nd paint layer of CS7, showing the spectral features of ultramarine blue. 

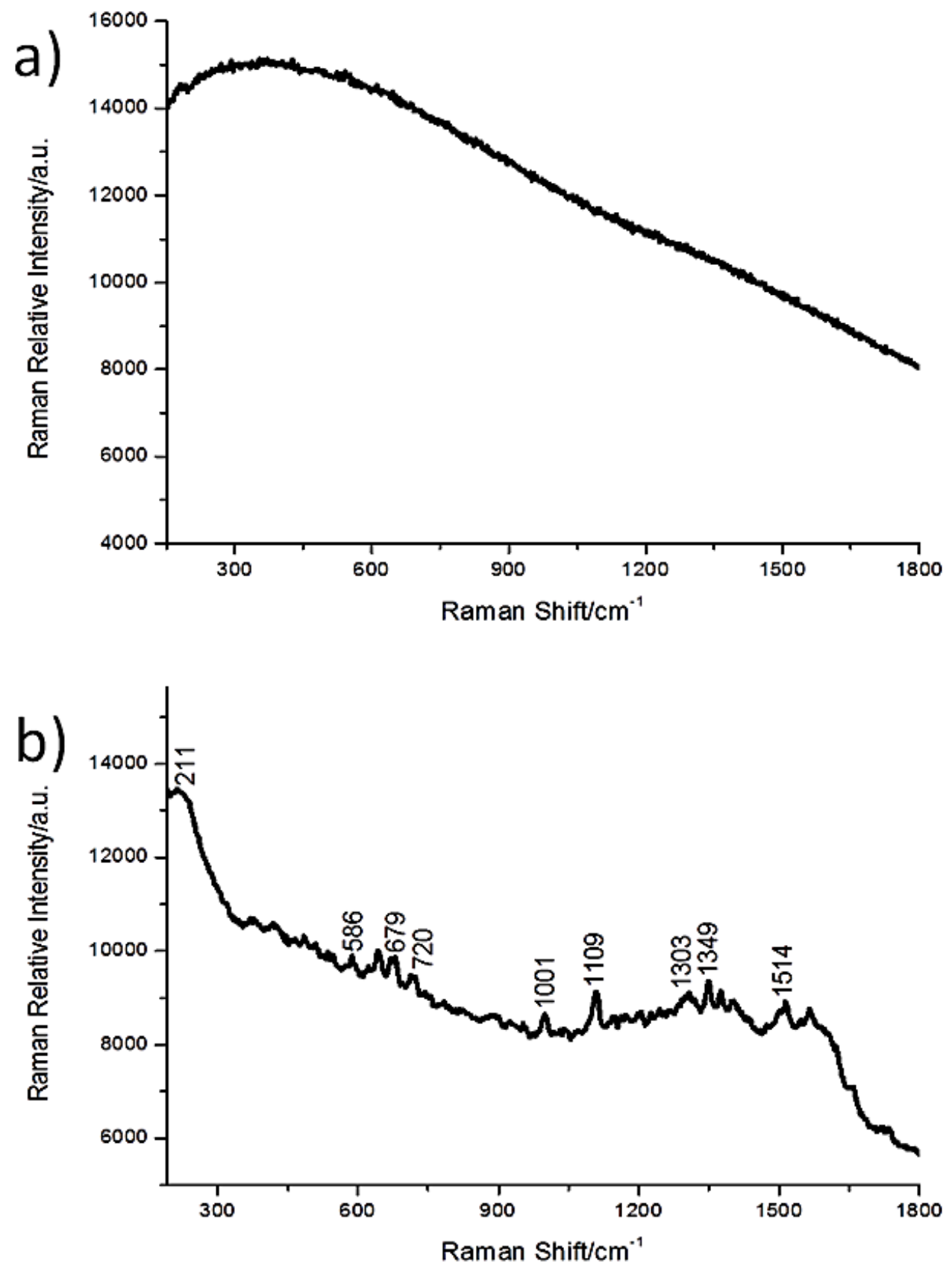

Figure 10. (a) Raman spectrum of the blue organic dye in 2nd paint layer of CS7, which resulted completely fluorescent; (b) SERS spectrum of the blue dye, recorded after AgNSs deposition, showing the spectral features of copper phthalocyanine.

\section{Conclusions}

The overall results obtained with this investigation on the Madonna della Misericordia of the Parma National Gallery are summarized in Table S1 in Supplementary Materials. In particular, the careful analysis of the cross section CS7 from the Madonna della Misericordia, combined with general visual and instrumental investigation on the painting, revealed at least two moments of execution. In particular, referring to the blue area from which CS7 was sampled, a probably older paint layer characterized by the presence of azurite and lead white was discerned. Over this, separated by a gypsum ground overlayer, a second layer of paint was found which contains modern components such as titanium white, copper phthalocyanine blue, and barite. These findings can indicate that the painting was realized in the 19th century and heavily remodeled during the restoration works of 
the 20th century. This dating is in substantial opposition to the temporal collocation reported in the inventory of the gallery which attributed the painting to the 15th century [28]. The extensive study of this work of art led to particularly interesting results: the scientific together with the stylistic analyses enabled to achieve a more accurate and precise dating, underlining the importance of adopting a scientific approach in the field of cultural heritage.

From an analytical diagnostic viewpoint, this study demonstrates the real-world applicability and practical usefulness of AgNSs as highly effective agents to achieve SERS detection of Raman signals for identifying pigments such as copper phthalocyanine, whose fluorescence hampers their detection by means of regular Raman spectroscopy. The one-pot, easy synthesis of AgNSs, together with their easy applicability on cross-sections or other kinds of samples, make their use highly practicable as SERS enhancers for real world cultural heritage diagnostics.

Supplementary Materials: The following are available online at http://www.mdpi.com/2571-9408/3/4/74/s1.

Author Contributions: Conceptualization, M.S.Z., I.A., P.U.; formal analysis, M.S.Z., N.K., P.U.; investigation, M.S.Z., N.K.; methodology, M.S.Z., I.A., N.K., P.U.; project administration, I.A., P.U.; supervision, I.A. and P.U.; validation, M.S.Z., I.A., P.U.; visualization, M.S.Z., P.U.; writing—original draft preparation, M.S.Z., I.A., P.U.; writing-review and editing, M.S.Z., I.A., N.K. and P.U. All authors have read and agreed to the published version of the manuscript.

Funding: This research received no external funding.

Acknowledgments: The Monumental Complex of the Pilotta and the National Gallery of Parma, in particular, the museum director Simone Verde and Maria Cristina Quagliotti of the administrative staff are sincerely thanked for the possibility of analyzing the painting Madonna della Misericordia. Philip N. Bartlett, University of Southampton, UK, is thankfully acknowledged for providing access to Raman and SERS instrumentation and for useful suggestions for improving the quality of the manuscript. We thank Danilo Bersani, University of Parma, for useful discussion on the Raman spectra. At University Ca' Foscari of Venice, we acknowledge the assistance of Eleonora Balliana and Elisabetta Zendri for the preparation of the cross-sections and Patrizia Canton for TEM analysis.

Conflicts of Interest: The authors declare no conflict of interest.

\section{References}

1. Pinna, D.; Galeotti, M.; Mazzeo, R. Scientific examination for the investigation of paintings. In $A$ Handbook for Restorers; Centro Di of Edifimi srl: Florence, Italy, 2011.

2. Zalaffi, M.S.; Karimian, N.; Ugo, P. Review-Electrochemical and SERS Sensors for Cultural Heritage Diagnostics and Conservation: Recent Advances and Prospects. J. Electrochem. Soc. 2020, 167, 037548. [CrossRef]

3. Smith, G.D.; Clark, R.J.H. Raman microscopy in archaeological science. J. Archaeol. Sci. 2004, 31, 1137-1160. [CrossRef]

4. Wiesinger, R.; Pagnin, L.; Anghelone, M.; Moretto, L.M.; Orsega, E.F.; Schreiner, M. Pigment and Binder Concentrations in Modern Paint Samples Determined by IR and Raman Spectroscopy. Angew. Chem. Int. Ed. 2018, 57, 7401-7407. [CrossRef] [PubMed]

5. Fleischmann, M.; Hendra, P.J.; McQuillan, A.J. Raman spectra of pyridzine adsorbed at a silver electrode. Chem. Phys. Lett. 1974, 26, 163-166. [CrossRef]

6. Le Ru, E.C.; Blackie, E.; Meyer, M.; Etchegoin, P.G. Surface Enhanced Raman Scattering Enhancement Factors: A Comprehensive Study. J. Phys. Chem. C 2007, 111, 13794-13803. [CrossRef]

7. Jurasekova, Z.; Del Puerto, E.; Bruno, G.; García-Ramos, J.V.; Sanchez-Cortes, S.; Domingo, C. Extractionless non-hydrolysis surface-enhanced Raman spectroscopic detection of historical mordant dyes on textile fibers. J. Raman Spectrosc. 2010, 41, 1455-1461. [CrossRef]

8. Pozzi, F.; Lombardi, J.R.; Leona, M. Winsor \& Newton original handbooks: A surface-enhanced Raman scattering (SERS) and Raman spectral database of dyes from modern watercolor pigments. Heritage Sci. 2013, 1, 23. [CrossRef]

9. Idone, A.; Aceto, M.; Diana, E.; Appolonia, L.; Gulmini, M. Surface-enhanced Raman scattering for the analysis of red lake pigments in painting layers mounted in cross sections. J. Raman Spectrosc. 2014, 45, 1127-1132. [CrossRef] 
10. Lee, P.C.; Meisel, D. Adsorption and surface-enhanced Raman of dyes on silver and gold sols. J. Phys. Chem. 1982, 86, 3391-3395. [CrossRef]

11. Cañamares, M.V.; Garcia-Ramos, J.V.; Gómez-Varga, J.D.; Domingo, C.; Sanchez-Cortes, S. Comparative Study of the Morphology, Aggregation, Adherence to Glass, and Surface-Enhanced Raman Scattering Activity of Silver Nanoparticles Prepared by Chemical Reduction of Ag+Using Citrate and Hydroxylamine. Langmuir 2005, 21, 8546-8553. [CrossRef]

12. Guerrero-Martínez, A.; Barbosa, S.; Pastoriza-Santos, I.; Liz-Marzán, L.M. Nanostars shine bright for you. Curr. Opin. Colloid Interface Sci. 2011, 16, 118-127. [CrossRef]

13. Wang, Y.; Camargo, P.H.C.; Skrabalak, S.E.; Gu, H.; Xia, Y. A Facile, Water-Based Synthesis of Highly Branched Nanostructures of Silver. Langmuir 2008, 24, 12042-12046. [CrossRef]

14. Garcia-Leis, A.; Garcia-Ramos, J.V.; Sanchez-Cortes, S. Silver Nanostars with High SERS Performance. J. Phys. Chem. C 2013, 117, 7791-7795. [CrossRef]

15. Zalaffi, M.S.; Litti, L.; Canton, P.; Meneghetti, M.; Moretto, L.M.; Ugo, P. Preparation and characterization of Ag-nanostars@Au-nanowires hierarchical nanostructures for highly sensitive surface enhanced Raman spectroscopy. Nano Express 2020, 1, 020006. [CrossRef]

16. Kumar, P.S.; Pastoriza-Santos, I.; Rodríguez-González, B.; De Abajo, F.J.G.; Liz-Marzán, L.M. High-yield synthesis and optical response of gold nanostars. Nanotechnology 2008, 19, 015606. [CrossRef]

17. Litti, L.; Reguera, J.; De Abajo, F.J.G.; Meneghetti, M.; Liz-Marzán, L.M. Manipulating chemistry through nanoparticle morphology. Nanoscale Horiz. 2020, 5, 102-108. [CrossRef]

18. Rodríguez-Lorenzo, L.; Álvarez-Puebla, R.A.; Pastoriza-Santos, I.; Mazzucco, S.; Stéphan, O.; Kociak, M.; Liz-Marzán, L.M.; De Abajo, F.J.G. Zeptomol Detection Through Controlled Ultrasensitive Surface-Enhanced Raman Scattering. J. Am. Chem. Soc. 2009, 131, 4616-4618. [CrossRef]

19. Pastoriza-Santos, I.; Liz-Marzán, L.M. N,N-Dimethylformamide as a Reaction Medium for Metal Nanoparticle Synthesis. Adv. Funct. Mater. 2009, 19, 679-688. [CrossRef]

20. Yuan, H.; Khoury, C.G.; Hwang, H.; Wilson, C.M.; A Grant, G.; Vo-Dinh, T. Gold nanostars: Surfactant-free synthesis, 3D modelling, and two-photon photoluminescence imaging. Nanotechnology 2012, 23, 075102. [CrossRef]

21. Yamamoto, M.; Kashiwagi, Y.; Sakata, T.; Mori, H.; Nakamoto, M. Synthesis and Morphology of Star-Shaped Gold Nanoplates Protected by Poly(N-vinyl-2-pyrrolidone). Chem. Mater. 2005, 17, 5391-5393. [CrossRef]

22. Bakr, O.M.; Wunsch, B.H.; Stellacci, F. High-Yield Synthesis of Multi-Branched Urchin-Like Gold Nanoparticles. Chem. Mater. 2006, 18, 3297-3301. [CrossRef]

23. Zhou, M.; Chen, S.; Zhao, S. Preparation of Branched Gold Nanocrystals by an Electrochemical Method. Chem. Lett. 2006, 35, 332-333. [CrossRef]

24. Li, Z.; Li, W.; Camargo, P.H.C.; Xia, Y. Facile Synthesis of Branched Au Nanostructures by Templating Against a Self-Destructive Lattice of Magnetic Fe Nanoparticles. Angew. Chem. Int. Ed. 2008, 47, 9653-9656. [CrossRef] [PubMed]

25. Lu, L.; Kobayashi, A.; Tawa, K.; Ozaki, Y. Silver Nanoplates with Special Shapes: Controlled Synthesis and Their Surface Plasmon Resonance and Surface-Enhanced Raman Scattering Properties. Chem. Mater. 2006, 18, 4894-4901. [CrossRef]

26. Zalaffi, M.S. Metal Nanostructures Decorated with Silver Nanostars: A Novel Highly Efficient Substrate for Dyes and Pigments Detection. Ph.D. Thesis, Università degli Studi di Trieste and Università Ca' Foscari, Venezia, Italy, 2019.

27. da Campagnola, S. L'arte nella chiesa e nel convento di s. Maria Maddalena e dell'Immacolata (già S. Caterina). In I Cappuccini a Parma: Quattro secoli di vita; da Mareto, F., Ed.; Istitutografico tiberino: Rome, Italy, 1961.

28. Ricci, C. La Regia. Galleria di Parma; BatteiL: Parma, Italy, 1896.

29. Fornari-Schianchi, L.; Riccomini, E. Galleria Nazionale di Parma, Catalogo delle opere dall'antico al Cinquecento; Ricci, F.M., Ed.; Franco Maria Ri: Milan, Italy, 1997.

30. Laver, M. Titanium dioxide whites in Artists' Pigments. In A Handbook of Their History and Characteristics, 3rd ed.; Fitzhugh, E.W., Ed.; National Gallery of Art: Washington, DC, USA, 1997; Volume 3.

31. Feller, R.L. Barium Sulphate-Natural and Synthetic in Artists' Pigments. In A Handbook of Their History and Characteristics; Feller, R.L., Ed.; Cambridge University Press: Cambridge, UK, 1986; Volume 1, pp. 255-283.

32. Newman, R. Chromium oxide greens in "Artists" Pigments. In A Handbook of Their History and Characteristics, 3rd ed.; Fitzhugh, E.W., Ed.; National Gallery of Art: Washington, DC, USA, 1997; Volume 3. 
33. Burgio, L.; Clark, R.J.H. Library of FT-Raman spectra of pigments, minerals, pigment media and varnishes, and supplement to existing library of Raman spectra of pigments with visible excitation. Spectrochim. Acta Part A Mol. Biomol. Spectrosc. 2001, 57, 1491-1521. [CrossRef]

34. Caggiani, M.; Cosentino, A.; Mangone, A. Pigments Checker version 3.0, a handy set for conservation scientists: A free online Raman spectra database. Microchem. J. 2016, 129, 123-132. [CrossRef]

35. Plesters, J. Ultramarine Blue, Natural and Artificial in Artists' Pigments. In A Handbook of their History and Characteristics; Feller, R.L., Ed.; Cambridge University Press: Cambridge, UK, 1986; Volume 1, pp. 37-61.

36. Available online: www.maimeri.it (accessed on 15 July 2020).

37. Scherrer, N.C.; Stefan, Z.; Francoise, D.; Annette, F.; Renate, K. Synthetic organic pigments of the 20th and 21st century relevant to artist's paints: Raman spectra reference collection. Spectrochim. Acta Part A Mol. Biomol. Spectrosc. 2009, 73, 505-524. [CrossRef] [PubMed]

38. Defeyt, C.; Strivay, D. PB15 as 20th and 21st artists' pigments: Conservation concerns. e-PS 2014, 11, 6-14.

39. Harroun, S.G.; Bergman, J.; Jablonski, E.; Brosseau, C.L. Surface-enhanced Raman spectroscopy analysis of house paint and wallpaper samples from an 18th century historic property. Analyst 2011, 136, 3453. [CrossRef]

40. Dahlen, M.A. The Phthalocyanines a New Class of Synthetic Pigments and Dyes. Ind. Eng. Chem. 1939, 31, 839-847. [CrossRef]

41. Cañamares, M.; Garcia-Ramos, J.; Domingo, C.; Sanchez-Cortes, S. Surface-enhanced Raman scattering study of the anthraquinone red pigment carminic acid. Vib. Spectrosc. 2006, 40, 161-167. [CrossRef]

Publisher's Note: MDPI stays neutral with regard to jurisdictional claims in published maps and institutional affiliations.

(C) 2020 by the authors. Licensee MDPI, Basel, Switzerland. This article is an open access article distributed under the terms and conditions of the Creative Commons Attribution (CC BY) license (http://creativecommons.org/licenses/by/4.0/). 